\title{
Status of Organization Citizen Behavior (OCB) in Nepalese Commercial Banks
}

\author{
Khagendra Bahadur Niroula ${ }^{1}, \&$ Ganga Prasad Chamlagai ${ }^{2}$ \\ ${ }^{1}$ Principal Author \\ Lecturer \\ Faculty of Management, Mahendra Multiple Campus, Dharan, Tribhuvan University, Nepal \\ ${ }^{2}$ Corresponding Author \\ Lecturer \\ Faculty of Management, Mahendra Multiple Campus, Dharan, Tribhuvan University, Nepal \\ ${ }^{1}$ Email: khagen2023@gmail.com \\ DOI: https://doi.org/10.3126/dristikon.v10i1.34552
}

\begin{abstract}
The paper aims to analyze the status of organization citizen behavior in Nepalese Commercial Banks. This study is based on Likert scale data. Twenty-seven questions are entertained in the set of questionnaires containing major demographic variables such as gender, experience, designation and qualifications of employees in sampled commercial banks. Primary data are collected through convenient and snowball sampling. Collected data are analyzed by using descriptive statistics, Karl Pearson coefficient of correlation, regression model by Andrew Haney's and Welch's ANOVA. The Statistical Package for Social Science (SPSS) 25 versions is used for the analysis of data. The result indicates that OCB favorably exits in Nepalese commercial banks. All dimensions of OCB have positive correlations among each other. The Welch's ANOVA posits that all employees of commercial banks have same levels of OCB irrespective of their nature. Further, the study proves that OCB at individual and organizational level significantly impact the composite OCB. Gender and education strengthen the relationship between OCB at individual level and composite OCB but these and other variables do not influence in the relationship of OCB at organizational level and composite OCB.

Keywords: organization citizen behavior, altruism, civic virtue, courtesy, conscientiousness, sportsmanship

\section{Introduction}

\section{Background}

Traditionally organizations were taken as melting pots where employees automatically follow organizations rules, policies and systems as they joined in the organization. However, in modern era, the concept of melting pot is not true where organizations have to make rules, policies and system acceptable to employees to create healthy working environment. Unless, organizations' rules, policies and system are not compatible with the employees' interest and expectations, employees will not be happy that create problems on their retention. Unhappiness
\end{abstract}


is just a tip of an iceberg where different direct and indirect or measurable and immeasurable factors can be found underneath of unhappiness. Higher pay, better growth opportunities, better reward and benefits, challenging job, better quality of work life etc. are the direct factors which can be measured easily, besides, there are many other benefits or indirect factors such as relationship with superiors, between coworkers, support of top management, altruism, civic virtue, courtesy, conscientiousness, commitment, sportsmanship etc. are hidden forces. These factors are more strong and powerful but cannot be applied by the force of managers. The applications of these forces are based on the wishes of employees. Existence of these and other such forces are called organization citizen behavior.

The organizational citizen behavior (OCB) is a new concept and first coined by Bateman and Organ in 1983. Later on, it was suggested by numbers of researchers. Organ (1983) defined the OCB as an individual behavior that is discretionary or explicitly recognized by the formal reward system and that in aggregate promotes the effective functioning of the organization. It is not explicit part of job description and it is not also considered in performance evaluation. It is neither defined by the top management in their rules nor evaluated in the job. It is the consequences of self-motivation and self-management of employees who perceive the work is worship, my happiness is my responsibility. It does not come from outside and it totally depends on the employee's loyalty and attachment towards the organization. However, OCB fosters effectiveness in organizations by providing a positive social and psychological environment in which task or work can flourish. It makes employees happy with work and foster employees' retention in the organization.

Commercial banks are hub of economic circulation in the country. They do not only carry out economic transactions but promote productive sectors, international trade, protects manufacturing and other organizations from financial crisis and provokes entrepreneurship in the country. Despite the history of commercial banks in Nepal is not so long, it has been lucrative place for employment opportunities. There is a paradigm shift in the job interest of young and qualified people and their interest in job has shifted from manufacturing organization to commercial banks. Further, Nepalese commercial banks are the significant contributor for the GDP. The recent report shows that in the last fiscal year 2075/2076, "A" class commercial banks have generated a total of 65 Arab. The net profit of commercial banks contributed 18\% of total GDP (Investo page). However, a matter of fact is that the capital, technology and strategy of any organization without the keen desires or willingness of employees towards the organization's goals will be worthless. Moreover, skill without willingness of employees is also meaningless. Unless employees are willing to do work, they won't use their skill. In this regard fostering organizational citizen behavior will be the key issue in any types of organizations trading, manufacturing or service to synchronize the skill and willingness of employees. The OCB is entirely based on individuals' wish or willingness. This research paper attempts to define OCB as an instrument to create favorable working 
environment, positive employees' attitudes, employees' commitment and willingness and analyze the present status of OCB in commercial banks.

\section{Statement of Problem}

Organization citizen behavior is employees' positive perception about organizations' environment. It fosters willingness of employees towards the accomplishment of organizations' tasks. OCB cultivates helping behavior, obedience, tolerance and makes employees ready to go beyond legal requirement for the benefit of organization. Despite the fact, employees have to face work over pressures in Nepalese banking sectors and promoting OCB is a challenging job. Therefore, the study focuses on following problems:

- Do the OCB dimensions favorable in Nepalese Commercial Banks?

- Does there any relationship exist between OCB dimensions?

- Do the OCB I and OCB-O have same impact on OCB?

- Do the demographic factors influence relationship between OCB dimension and composite OCB?

- Do any differences on OCB-I, OCB-O and OCB exist among commercial banks?

\section{Objectives of the Study}

The study of OCB is directly concerned with people in organizations where people are unique assets who maintain control over all other resources. It promotes employee's willingness in the organization. When the unique assets exert fullest efforts, organizations will get complete advantages. The main objective of this study is to determine the present condition of OCB in Nepalese Commercial Banks. However, specific objectives are as under:

- To examine the favorableness or favorableness of OCB in Nepalese Commercial Banks.

- To establish the extent of relationship, exist in OCB dimensions in Nepalese Commercial Banks.

- To analyze the impact of OCB-I and OCB- O on OCB.

- To determine the impact of demographic variables in relationship between OCB dimensions and overall $\mathrm{OCB}$.

- To analyze the variance on OCB, OCB-I and OCB among Private, Joint venture and Government owned commercial banks.

\section{Limitation of the Study}

Like other research, the study is not free from limitations. The major limitations of this study are as follows: 
- Samples are taken from only nine commercial banks out of 28 banks.

- Because of pandemic questionnaires were sent through Google drive and only 200 questions were returned out of 360 questions.

- Reliability of response is based on the honesty of respondents.

- Limited statistical tools have been used to conduct the study.

- Few demographic variables such as gender, experience, educational qualification and designation of employees are taken as moderating factors.

\section{Review of Literature}

Organizational citizenship behavior Organizational Citizenship Behavior (OCB) is one of the most widely studied topics in organizational behavior research (Podsakoff and MacKenzie,). It is a multi-dimensional construct. Simith, Organ and Vear (1983) suggested two dimensions of OCB- altruism and generalize compliances. Later on, Organ (1988) suggested five dimensions altruism, civic virtue, courtesy, conscientiousness, and sportsmanship of OCB.

Jain and Jain (2014) measured OCB of bank managers about their helping behavior, courtesy and sportsmanship and the impact of HR practices such as organizational climate, employee training, employee empowerment and performance appraisal on OCB. They used correlation and multiple regression analysis to draw inference. Correlation analysis indicated that there is high or moderate degree of positive correlation exists between the study variable. Multiple regression analysis concluded significant amount of variation in OCB.

Popescu and Deaconu (2013) conducted a study in Romaniya high schools. They identified that OCB reduced workplace tension, enhanced overall effectiveness and resulted in a reduction in the managerial load of the leader. Luxmi and Dwivedi (2009) revealed a very significant and positive correlation between two subscales of Organizational Citizenship Behaviour and clearly support the idea that aggregated OCBs are related to organizational effectiveness indicators. Organ (1983) argued that organization citizenship behaviour would enhance performance by "lubricating" the social machinery of the organization, reducing friction, and/or increasing efficiency. Organ (1988) identified following five major dimensions of OCB:

\section{i. Altruism}

It is concerned with willingly helping others with, or preventing the happening of work-related problems. Altruism can be called simply helping or helpfulness (Organ, 1997). Altruism consists of voluntarily actions that help others with an organizationally relevant task such as voluntarily helping orientation of a new employee, sharing sales strategies, teaching employees useful knowledge or skills, showing employees how to accomplish difficult tasks (Borman et al., 1998). 


\section{ii. Conscientiousness}

It is carrying out one's duties beyond the minimum requirements, where employees pay attention to the details and following rules, regulations and procedures. It is a discretionary behavior that goes well beyond the minimum role requirement level of the organization, such as obeying rules and regulations, not taking extra breaks, working extra-long days (MacKenzie et al., 1993). Borman et al. stated that altruism and conscientiousness is the two major dimension of OCB (Borman et al., 2001).

\section{iii. Sportsmanship}

Sportsmanship is demonstrations of willingness to tolerate minor and temporary personnel inconveniences and impositions of work without grievances, complaints, appeals, accusations, or protest, thus conserving organizational energies for task accomplishment and lightening the loads of managers (Organ \& Ryan, 1995).

\section{iv. Courtesy}

Courtesy factor indicated the behavior of the employees where they alert others in the organization about changes that may affect their work. A courteous employee avoids creating problems for co-workers reduces intergroup conflict so managers do not fall into a pattern of crisis management (Podsakoff \& MacKenzie, 1997).

\section{v. Civic Virtue}

Civic virtue is a behavior on the part of an individual that indicates that employee responsibly participate in, is involved in, or concerned about the life of the company (Podsakoff et al., 1990). This behavior shows willingness to participate actively in managerial events, to monitor organization's environment for threats and opportunities, to look out for organization's best interest. These behaviors reflect an employee's recognition of being a part organization (Podsakoff et al., 2000).

Williams and Anderson (1991), divided OCB into two types behaviors directed at specific individuals or persons in the organization, such as courtesy and altruism (OCB-I); and behaviors concerned with benefiting the organization as a whole, such as conscientiousness, sportsmanship and civic virtue (OCB-O). Citizenship behaviors directed toward individuals OCB-I refer to the behaviors that immediately benefit specific individuals within an organization and, thereby, contribute indirectly to organizational effectiveness.

\section{Conceptual Framework}

Based on the concept derived from literature review, the researcher developed conceptual framework for the research. The objective of research is to analyze the status of organization citizen behavior in Nepalese commercial banks. So, the conceptual framework is designed based on the five dimensions of OCB suggested by Organ. Altruism, courtesy, 
conscientiousness, civic virtue and sportsmanship are taken as independent variables and composite OCB is taken as dependent variable. Further gender, age, educational qualification and designations are taken as moderating variables.

\section{Figure 1}

\section{Independent and Dependent Variables about OCB Dimensions}

Independent variables
OCB-I
Altruism
Courtesy
OCB-O
Conscientiousness
Civic Virtues
Sportsmanship

\section{Hypotheses Testing}

A hypothesis is a statement logically formed on the basis of relationship between two or more variables. It is an opinion made on the basis of conceptual framework. This study proposes following hypotheses:

$\mathrm{H}_{1:}$ There exist favorableness in OCB dimensions of Nepalese Commercial Banks, $\mathrm{H}_{2}$ : There is significant positive relationship among five dimensions of OCB $\mathrm{H}_{3}$ : There is significant difference between the OCB- I, OCB- $\mathrm{O}$ and OCB of employees belonging to private commercial banks and foreign joint venture commercial banks in Nepal.

$\mathrm{H}_{4}$ : There is the same impact of OCB-I and OCB- O on composite OCB.

$\mathrm{H}_{5}$ : There significant impact of moderating factor OCB-I on OCB of employees.

$\mathrm{H}_{6}$ : There significant impact of moderating factor OCB-O on OCB of employees.

\section{Methods and Materials}

This research is explanatory and descriptive in nature where there is no similar previous research found in this field. It uses different demographic variables and it attempts to identify the impact of independent variables on dependent variables. It considers all commercial banks and employees working in the commercial banks the population of study. One hundred and fifty questionnaires were distributed to the employees working in different 
private, public and joint ventures commercial banks where only 106 questions were returned by respondents. Questionnaires were designed by dividing in to two sections. The first section was related to demographic characteristics whereas the second section was related to general questions covering the five dimensions of OCB. Further five dimensions are re-categorized into two dimensions to reduce the multi-colinearity effect. It has used primary data and data were collected through questionnaire by using five points Likert scale.

Descriptive statistics such as mean and coefficient of variance are used to analyze the aggregate condition of OCB in Nepalese commercial banks. Pearson's coefficient of correlation is deployed to establish the relationship between OCB dimensions and multiple regressions is resorted to assess the impact of OCB dimension on OCB. Welch's ANOVA is used to analyze whether the differences exist in OCB among the sampled banks. Moderation analysis is another statistical tool used to explain the impact of independent variables on dependent arable under the influence of moderators.

This research includes three different variables: dependent, independent and moderating. OCB dimensions are broadly categorized into OCB- I and OCB-O. These dimensions are taken as independent variable and overall OCB is taken as dependent variables. Further, demographic variables such as gender, experience, educational qualification and designation of employees are organized as moderating or third variables.

\section{Results and Discussion}

\section{Conditions of Organization Citizenship Behavior (OCB) Dimensions}

The study has considered the five dimensions, viz., altruism, courtesy, conscientiousness, civic virtue and sportsmanship. It uses Likert 5-anchor scale data. The aggregate value of Cranach's Alpha is 0.745 which is greater than its minimum range 0.70 which shows the reliability of value of descriptive statistics. The values of Cronbach's will be reduced if any dimension is eliminated. Table 1 shows all mean values are greater than 20 and values standard deviations are relatively uniform. Based on the mean value, bankers reported their altruism (mean value 26.25) as the highest OCB dimension followed by conscientiousness (24.47). Hence, the organizational citizenship behavior exists favorably among bank employees in Nepal and $\mathrm{H}_{1}$ is accepted. 
Table 1

Conditions of $O C B$ Dimensions

\begin{tabular}{lcccccc}
\hline OCB dimensions & Minimum & Maximum & Mean & $\begin{array}{l}\text { Std. } \\
\text { Deviation }\end{array}$ & Rank & $\begin{array}{l}\text { Cronbach's } \\
\text { Alpha }\end{array}$ \\
\hline Altruism & 21 & 30 & 26.25 & 2.09 & 1 & .725 \\
Courtesy & 16 & 30 & 24.44 & 3.11 & 3 & .634 \\
Conscientiousness & 15 & 30 & 24.47 & 2.28 & 2 & .637 \\
Civic Virtues & 15 & 32 & 23.59 & 3.91 & 4 & .808 \\
Sportsmanship & 14 & 26 & 21.34 & 2.25 & 5 & .692 \\
\hline
\end{tabular}

Note. Author's calculation using SPSS $25^{\text {th }}$ version.

\section{Relationship Among OCB Dimensions}

OCB dimensions are independent variables used in this research. This research focuses on evaluating the relationship among the five dimensions of OCB. The table shows positive correlation among these dimensions where the correlation between conscientiousness and courtesy (0.891) and Civic virtue and Conscientiousness (0.891) show high positive relationship than other variables. P-values of all variables are .0000 except courtesy where the p-values of courtesy are $0.003,0.004$ and 0.006 which are lower than 0.05 . Therefore, it depicts there is significant positive relationship between dimensions of OCB in Nepalese commercial banks. Hence $\mathrm{H}_{2}$ is accepted.

\section{Table 2}

Correlation Matrix Showing the Relationship Among OCB Dimensions

\begin{tabular}{llllll}
\hline OCB Dimensions & 1 & 2 & 3 & 4 & 5 \\
\hline Alt & 1 & & & & \\
$\mathrm{Cr}$ & $.285(0.003)$ & 1 & & & \\
$\mathrm{Cs}$ & $.342(0.000)$ & $.891(0.004)$ & 1 & & \\
$\mathrm{Cv}$ & $.372(0.000)$ & $.269(0.006)$ & $.891(0.000)$ & 1 & \\
$\mathrm{Ss}$ & $.500(0.000)$ & $.496(0.000)$ & $.324(0.000)$ & .378 & 1 \\
& & & & $(0.000)$ & \\
\hline
\end{tabular}

Note. Author's calculation using SPSS $25^{\text {th }}$ version. (Figures in parenthesis indicate p-values), Alt $=$ Altruism, $\mathrm{Cr}=$ Courtesy, $\mathrm{Cs}=$ Conscientiousness, $\mathrm{Cv}=$ Civic virtue, Ss $=$ Sportsmanship. 


\section{Analysis of Variance on OCB}

The study aimed to investigate the variation on OCB-I, OCB-O and OCB between the Nepalese three types of commercial banks: private sector banks, joint venture and Government sectors. Since, the data do not satisfy the normality and homogeneity related assumptions, the researcher has used Welch's analysis of variance (Welch's ANOVA). The table shows the asymptotical distribution $F$ values at 2 degree of freedom where $p$-value of each dimensions OCB-I, OCBO and composite OCB is greater than 0.05. So, it is evident that there is no significant variation between OCB- I, OCB-O and composite OCBs of employees of government commercial banks, foreign joint venture and private commercial banks. Hence, the finding has rejected $\mathrm{H}_{2}$ establishing that government, foreign joint venture and private commercial banks would not vary by the overall OCB and its constituent dimensions of OCB-I and OCB-O.

\section{Table 3}

\begin{tabular}{lccc}
\multicolumn{4}{l}{ Welch's Analysis of Variance } \\
\hline Variables & $\begin{array}{c}\text { Statistics } \\
\text { (F Value) }\end{array}$ & df & Significance \\
\hline OCB & 0.440 & 2 & .646 \\
OCB-I & 0.057 & 2 & .945 \\
OCB-O & 1.035 & 2 & .361 \\
\hline
\end{tabular}

Note. Author's calculation using SPSS $25^{\text {th }}$ version.

\section{Analysis of Impact of OCB-I and OCB-O on Composite OCB}

The study classified the OCB dimensions at individual level (OCB-I) and organizational level (OCB-O). It attempts to determine whether these two dimensions have impact on composite OCB or not. In social research the problem of multi co-linearity is common. So, first of all the multicollinearity is tested by using tolerance and VIF factors. Table 3 shows tolerance factors of both OCB-I and OCB-O is greater than .02 and VIF less than 10. It justifies, variables free from muliti collinearity problem (O'Barien, 2007. Further, the study uses different factors such as lower and upper bound of confidence level, beta and p-values to determine the impact of OCB-I and OCB-O on composite OCB where lower and upper bound do not cross zero, beta values are positive and $\mathrm{p}$-values are less than 0.05 . The value of $\mathrm{R}$ square explains $98 \%$ variation changing the independent variables on dependent variables. It indicates that there are significant differences on the impact of OCB-I and OCB-O on composite OCB. Hence the $\mathrm{H}_{3}$ is accepted. 
Table 4

Analysis of Impact of $O C B-I$ and $O C B-O$ on Composite $O C B$

\begin{tabular}{|c|c|c|c|c|c|c|c|}
\hline & & & & $95 \%$ of & $\begin{array}{l}\text { Confidence } \\
\text { Interval }\end{array}$ & $\begin{array}{l}\text { Co- } \\
\text { linearity }\end{array}$ & Statistics \\
\hline Variables & $\begin{array}{l}\text { Beta } \\
\text { (B) }\end{array}$ & $\mathrm{t}$ value & $\begin{array}{l}\mathrm{P} \\
\text { values }\end{array}$ & Lower & Upper Bound & Tolerance & VIF \\
\hline OCB-I $\rightarrow$ OCB & .593 & 31.73 & .000 & 1.017 & 1.152 & .803 & 1.245 \\
\hline $\mathrm{OCB}-\mathrm{O} \rightarrow \mathrm{OCB}$ & .567 & 30.33 & .000 & 0.727 & 0.729 & .803 & 1.245 \\
\hline
\end{tabular}

R- square $=0.981$

Adjusted R-square $=0.971$

Note. Author's calculation using SPSS $25^{\text {th }}$ version.

\section{Moderations' Effect}

Moderation analysis is carried out to estimate the moderation effect. Moderation analysis is a kind of regression analysis where some controlling variables are used to determine their influence in the relationship between dependent and independent variables. Few demographic variables such as gender, education, designation and experiences are taken as moderators. In this study beta, $t$ values, $p$-value, lower level confidence limit (LLCI) and upper level confidence limit (ULCI) of interacting variables are used in the analysis of data. If the pvalue is equal or less than 0.05 and the range of LLCI and ULCI do not cross the zero that portrays significant effect of moderator in the relationship between dependent and independent variables' and vice-versa.

Table 5

Influences of Moderators in the Relationship Between OCB-I and OCB

\begin{tabular}{llllll}
\hline Interactions & Beta $(B)$ & t-values & p-values & LLCI & ULCI \\
\hline OCB-I $\rightarrow$ Gender $\longrightarrow$ OCB & 0.829 & 3.8034 & 0.0002 & 0.3965 & 1.2613 \\
OCB-I $\rightarrow$ Education $\longrightarrow$ OCB & 0.4375 & 2.0766 & 0.0404 & 0.0194 & 0.8250 \\
OCB-I $\rightarrow$ Designation $\longrightarrow$ OCB & 0.0765 & 0.3675 & 0.7147 & -0.3364 & 0.4894 \\
OCB-I $\rightarrow$ Experience $\longrightarrow$ OCB & 0.1592 & 0.3754 & 0.1977 & -0.1977 & 0.5163 \\
\hline
\end{tabular}

Note. Author's calculation using SPSS $25^{\text {th }}$ version.

The above table reveals the influence of demographic variables gender, education, designation and experience in the relationship between OCB-I and composite OCB. The result shows that gender has positive influences in OCB-I composite OCB interaction $(\mathbf{B}=0.829, \mathrm{t}=$ $3.8034, p<0.05$ and the range of LLCI and ULCI does not cross the zero). Similarly, the influence of education in the relationship between OCB-I and composite OCB is significant (B 
$=0.4375, \mathrm{t}=2,0766, \mathrm{p}<0.05$ and LLCI and ULCI does not cross zero), The third moderator explains the influence of designation in the relationship between OCB-I and composite OCB is not significant $\quad(B=0.10765, t=0.3675 p>0.05$ and LLCI and ULCI crossed the zero). It is also evident that education level does play moderator's role in the relationship between OCB-O and OCB Experience is the last moderator used in this research where coefficient and t-values are negative $(B=0.1583, t=0,3754, p>0.05$ and the range of LLCI and ULCI crossed zero. It shows only moderated relationship. Hence, $\mathrm{H}_{5}$ is not accepted.

\section{Table 6}

Influences of Moderators in the Relationship Between OCB-O and Composite OCB

\begin{tabular}{lllllll}
\hline Interactions & & Beta $(B)$ & t-values & p-values & LLCI & ULCI \\
\hline OCB-O $\rightarrow$ Gender $\longrightarrow$ & $\longrightarrow$ OCB & -0.1592 & -0.9972 & 0.3211 & -0.4760 & 0.1576 \\
OCB-O $\rightarrow$ Education $\longrightarrow$ OCB & 0.0212 & 0.1476 & 0.889 & -0.2636 & 0.306 \\
OCB-O $\rightarrow$ Designation $\longrightarrow$ OCB & 0.1420 & -1.2786 & 0.2040 & -0.0784 & 0.3624 \\
OCB-O $\rightarrow$ Experience $\longrightarrow$ OCB & -0.1800 & -1.3897 & 0.1603 & -0.4326 & 0.0725 \\
\hline
\end{tabular}

Note. Author's calculation using SPSS $25^{\text {th }}$ version.

The above table attempts to portray the influence of demographic variables gender, education, designation and experience in the relationship between OCB-O and composite OCB. The result shows that gender has negative impact on OCB-O and composite OCB interaction ( $B=-0.192, t=-0.9972, p>0.05$ and LLCI and ULCI crossed the zero). Despite the positive beta and $t-$ value $(B=0.0212, t=0.1476)$ the $p>0.05$ and LLCI and ULCI crossed zero, the influence of education in the relationship between OCB-O and OCB is not significant. The coefficient of third moderator is positive $(\mathrm{B}=0.1420)$ but $\mathrm{t}$-value is negative $(\mathrm{t}=-1.2786)$, p>0.05 and LLCI and ULCI crossed the zero. It also explains the influence of designation in the relationship between OCB-O and OCB is not significant. Experience is the last moderator used in this research where coefficient and $t$-values are negative $(B=-0.1800, t=-1.3897), p>0.05$ and the range of LLCI and ULCI crossed zero. It is also evident that education level does play moderator's role in the relationship between OCB-O and OCB. Hence, $\mathrm{H}_{6}$ is not accepted.

\section{Findings}

This article attempts to reveal the status of organization citizen behavior on Nepalese commercial banks where OCB is taken as glue that lubricates the positive relationship between employees and organization and achieve organizational effectiveness. The study is conducted take three banks from each sector; private, joint venture and government where responses of 106 respondents are administered from Chakraghatti, Dharan, Itahahari, Biratnagar and Kathmandu. The findings of the study are as under: 
i. The test of descriptive statistics about all five dimensions show the mean values more than 20, standard deviations are consistent among variables and the value of Cronbach's alpha is greater than 0.7 . It proves the reliability of the research test and good condition of OCB dimensions in Nepalese commercial banks.

ii. The correlation matrix depicts positive relationship between altruism, courtesy, conscientiousness, civic virtues and sportsmanship where p-values are less than 0.05 . It proves significant relationship among the dimensions of OCB in Nepalese commercial banks.

iii. The study conducted analysis of variance by using Welch's ANOVA which shows the asymptotical distribution $F$ values at 2 degree of freedom where $p$-value of each dimensions OCB-I, OCBO and composite OCB is greater than 0.05. So, it is evident that there is no significant variation between OCB- I, OCB-O and composite OCBs of employees of government commercial banks, foreign joint venture and private commercial banks.

iv. The analysis of impact of OCB-I and OCB-O on composite OCB uses different factors such as lower and upper bound of confidence level, beta and $\mathrm{p}$-values to determine the impact of OCB-I and OCB-O on composite OCB where lower and upper bound do not cross zero, beta values are positive and p-values are less than 0.05 . It indicates that there are significant differences on the impact of OCB-I and OCB-O on composite OCB.

v. The study of the effect of moderators in the relationship between OCB-I (altruism and courtesy) and composite OCB (conscientiousness, civic virtues and sportsmanship) and OCB-O and composite OCB is the crux of this study. The analysis of moderators reveals that gender and education influence in the levels of relationship between altruism and courtesy with organization citizen behavior ( $\mathrm{p}<0.05$ and the range LLCI and ULCI do not cross zero). However, designation and experiences do not have influence in the relationship between these variables ( $p>0.05$ and the range LLCI and ULCI cross zero). Similarly, the study of moderation effect between OCB-O and composite OCB show that moderators do not have influence in the relationship between OCB-O and composite OCB since the pvalues of all interaction are greater than 0,05 and the range of LLCI and ULCI cross the zero.

\section{Conclusion}

Organization citizen behavior contains different dimensions and researchers use different variables in their study. This research is primarily based on the dimensions explained by Organ and classified by Williams and Anderson. It contains fie dimensions: altruism, courtesy, civic virtues, conscientiousness and sportsmanship where first two dimensions are put on OCB-I and second three dimensions are placed under OCB-O. The study presents OCB 
dimensions exist favorably and there is significant positive relationship among the five dimensions of OCB in Nepalese commercial banks. Further, the levels of OCB dimensions are not different in Nepalese commercial banks. Organization citizen behavior at individual level (OCB-I) and at organizational level (OCB-O) do not have different impact on composite OCB of Nepalese commercial banks. The study also predicts that OCB-I and OCB-O related factors significantly impact the overall perception of organization citizen behavior. The influence of demographic factors in the relationship between OCB-I and composite OCB is ambivalent. This means gender and education exhibit significant influence where as other variables designation and experience do not show influence in the relationship between OCB-I and composite OCB. However, the impact of demographic factors in the relationship between OCB-0 and composite OCB is crystal clear. These factors do not influence the relationship between OCB dimensions at organizational level and composite OCB. The study confirms that female employees with higher education level hold strong position $(B=2.54)$ than male employees $(\mathrm{B}=1.17)$ to influence the relationship between OCB-I and composite OCB in Nepalese commercial banks (Appendix).

\section{Implication}

OCB is the element resides inside every person that fosters willingness so that they exert efforts towards the accomplishment of organizations' goals. This study identified that every employee enters in the organization with positive perception about organizations goals. The degree of such perception would not vary in banks irrespective their nature. Gender and education have significant influence at individual level OCB where designation and experiences neither influence the OCB at individual level nor at organization level. Therefore, it suggests to the managers of banking organization to concentrate on gender and education of employees to foster their altruistic and courteous attitude in the organization and promote willingness at individual level.

\section{References}

Bateman, T. S., \& Organ, D. W. (1983). OB satisfaction and the good soldier: The relationship between affect and employee citizenship. Academy of Management Journal, 26(4), 587-595.

Bateman, T. S., \& Strasser, S. (1984). A longitudinal analysis of the antecedents of organizational commitment. The Academy of Management Journal, 1(27), 95-112.

Borman, C. W., Penner, L. A., Allen, T. D., \& Motowidlo, S. T. (2001). Personality predictors of citizenship performance. International Journal of Selection and Assessment, 9(1/2), 52-66.

Investopaper. (n.d.). investopaper.com/contribution of banking sector to the gdp of Nepal/.

Jain, S., \& Jain, R. (2014). Organizational citizenship behavior \& HRM practices in Indian banks, Indian Journal of Industrial Relations, 50(2), 257-269. 
Laxmi, R., \& Dwivedi, M. (2009). Impact of organizational citizenship behavior on organizational effectiveness in food processing industry. Arth Anvesan: A Bi-Annual Journal of SMVD University College of Management, 4(1\&2), 42-51.

MacKenzie, S. B., Podsakoff, M. F. \& Fetter, R. (1993). The Impact of organizational citizenship behavior on evaluations of salesperson performance. Journal of Marketing, 57 (January), 70-80.

O’Barien, R. M. (2007). A Caution Regarding Rules of Thumb for Variance Inflation Factors. Quality and Quantity. https://doi.org/10.1007/s11135-006-91018-6

Organ, D. W., \& Moorman, R. H. (1993). Fairness and organizational citizenship behavior: What are the connections? Social Justice Research, 6, 5-18.

Organ, D. W. (1990). The Motivational Basis of Organizational Citizenship Behavior in B. M. Staw and L. L. Cumming (Eds). Research in Organizational Behavior, 12, 43-72, Greenwich, CT: JAI Press.

Organ, D. W. (1997). Organizational citizenship behavior: It's construct clean-up time. Human Performance, 10(2), 85-97.

Organ, D. W., \& Ryan, K. (1995). A meta-analytic review of additional and dispositional predictors of organizational behavior. Personal Psychology, 48, 775-802.

Podsakoff, M. F., \& MacKenzie, S. B. (1997). Impact of organizational citizenship behavior on organizational performance: A review and suggestions for future research. Human Performance 10(2), 133-151.

Podsakoff, M. F., MacKenzie, S. B., Moorman, R. H., \& Richard, F. (1990). Transformational leader behaviors and their effects on followers' trust in leader, satisfaction, and organizational citizenship behaviors. Leadership Quarterly, 1(2), 107-142.

Podsakoff, M. F., MacKenzie, S. B., Paine, J. B., \& Bachrach, D. G. (2000). Organizational Citizenship Behaviors: A critical review of the theoretical and empirical literature and suggestions for future research. Journal of Management, 26(3), 513-563.

Williams. L. J., \& Anderson. S. E. (1991). Job satisfaction and organizational commitment as predictors of organizational citizenship and in-role behaviors. Journal of Management, 17(3), 601-617.

\begin{tabular}{lllllll}
\multicolumn{7}{c}{ Appendix } \\
\hline Gender & Education & Effect (B) & T & P & LLCI & ULCI \\
\hline Male & Bachelor & 1.28 & 12.39 & 0.0000 & 1.08 & 1.49 \\
Male & Masters & 1.71 & 8.27 & 0.0000 & 1.31 & 2.13 \\
Female & Bachelor & 2.11 & 10.58 & 0.0000 & 1.72 & 2.51 \\
Female & Masters & 2.54 & 10.23 & 0.0000 & 2.05 & 3.04 \\
\hline
\end{tabular}

